\title{
Anti-colon cancer effects of Salograviolide A isolated from Centaurea ainetensis
}

\author{
NAHED EL-NAJJAR ${ }^{1}$, SAADAH DAKDOUKI $^{2}$, NADINE DARWICHE $^{1}$, \\ MARWAN EL-SABBAN ${ }^{3}$, NAJAT A. SALIBA ${ }^{2}$ and HALA GALI-MUHTASIB ${ }^{1}$ \\ Departments of ${ }^{1}$ Biology, ${ }^{2}$ Chemistry and ${ }^{3}$ Human Morphology, American University of Beirut, Lebanon
}

Received September 27, 2007; Accepted November 2, 2007

\begin{abstract}
The antitumor activity of extracts of Centaurea ainetensis ( $C$. ainetensis), a plant endemic to Lebanon, was investigated in human colon carcinoma cells. At concentrations that were non-cytotoxic to normal human intestinal epithelial cells, the crude extract inhibited the proliferation of a host of colon-derived cancer cells. The crude extract effect was then investigated in HCT-116 ( $\left.\mathrm{p} 53^{+/+}\right)$cells, most sensitive to treatment and was found to cause apoptosis, increase the $\mathrm{Bax} / \mathrm{Bcl}-2$ ratio, p53 and p21 protein levels and reduce cyclin $\mathrm{B}_{1}$ proteins. In vivo, the crude extract injected intraperitoneally before the subcutaneous injection of the carcinogen 1,2dimethylhydrazine, drastically reduced the number of tumors and decreased the mean size of aberrant crypt foci. Further bioassay-guided fractionation of the crude extract resulted in the identification of the bioactive molecule Salograviolide A, a Sesquiterpene Lactone, to which the growth inhibition in colon cancer was linked. Salograviolide A, at non-cytotoxic concentrations to normal human intestinal cells, reduced the growth of colon cancer cell lines. Salograviolide A induced growth inhibition and resulted in an increased $\operatorname{pre}_{1}$ phase and presumably apoptosis induction which was further confirmed by TUNEL. These data support the testing of the $C$. ainetensis extract and its bioactive molecule, Salograviolide $\mathrm{A}$, in colon cancer treatment.
\end{abstract}

\section{Introduction}

The current therapy is unsatisfactory and necessitates the exploration of other avenues for the prevention and treatment of cancer. Colon cancer is the fourth leading cancer in developed countries. Herbal therapies, in particular, plant-

Correspondence to: Dr Hala Gali-Muhtasib, Department of Biology, American University of Beirut, P.O. Box 11-0236, Riad El Solh, Beirut 1107 2020, Lebanon

E-mail: amro@aub.edu.lb

Dr Najat Saliba, Department of Chemistry, American University of Beirut, P.O. Box 11-0236, Riad El Solh, Beirut 1107 2020, Lebanon E-mail: ns30@aub.edu.lb

Key words: cell cycle, apoptosis, colon cancer, herbal medicines, cancer therapy based products, have been recognized as preventive with regard to the development of colon cancer $(1,2)$. However, little understanding exists about the active components responsible for this biological effect and about their cellular and molecular mechanism(s) of action. Lebanon, which is part of the Mediterranean coast and has varied microclimates, has a wide diversity of plant species distributed along its relatively small geographical area. More than a hundred plant species in Lebanon are reported to have medicinal properties (3). Some of these plants used by people as folk medicines for hundreds of years (4), are still commonly used.

The genus Centaurea (Asteraceae), extensively used in folk medicine for hundred of years (5), includes 500 species distributed around the Mediterranean area and West Asia (6). The genus Centaurea is rich in secondary metabolites that have antioxidant, antimicrobial, anti-tumor and anti-inflammatory properties (5,7-11). Various types of Sesquiterpene Lactones were isolated from the Centaurea species and found to exhibit a broad spectrum of biological activities including cytotoxic and antitumor (12-14). For instance, Sesquiterpene Lactones isolated from $C$. zuccariniana, C. Achaia, C. thessala and $C$. deusta showed considerable growth inhibitory activities against breast cancer MCF-7 and lung cancer H460 cell lines (11). The structure-activity relationship of several Sesquiterpene Lactones has been attributed to the presence of $\alpha$ - and $\beta$ unsaturated carbonyl groups $(12,13)$.

To our knowledge, the anticancer properties of the $C$. ainetensis extract, its subfractions and isolated components have not been investigated. Therefore, the present study involved the evaluation of the anticancer activity and mechanism of action of the $C$. ainetensis extracts using human colon cancer cells and the 1,2-dimethylhydrazine (DMH) mouse model of colon cancer. In addition, the anti-proliferative activity of fractions and isolated guaianolide, Salograviolide A, obtained through bioassay-guided fractionation were tested against human colon cancer cells. These studies highlight the potential therapeutic mode of $C$. ainetensis extracts and Salograviolide A in colon cancer.

\section{Materials and methods}

Cell culture, the collection of the plant material, extraction, fractionation, isolation and molecular identification procedures. In brief, the aerial parts of the plant material of $C$. aninetensis were collected and identified and a voucher 
specimen was deposited in the George Post Herbarium at the American University of Beirut (AUB). The plant was extracted using methanol, the extract was fractionated using column chromatography and the active compound was isolated and purified using solide phase extraction followed by several spectroscopic measurements.

FHs74Int normal human intestinal epithelial cells and HCT-116 human colon cancer cells were kindly provided by Dr R. Schneider-Stock (Otto-von-Guericke University of Magdeburg, Germany). The colon cancer cell lines, HCT-116 and HT-29 were grown in RPMI-1640 + HEPES. FHs74Int cells were grown in Hybricare medium, supplemented with $30 \mathrm{ng} / \mathrm{l}$ epidermal growth factor (EGF) (ATCC, Manassas, Virginia, USA). All cells were maintained at $37^{\circ} \mathrm{C}$ in a humidified atmosphere of $5 \% \mathrm{CO}_{2}, 95 \%$ air, supplemented with $1 \%$ penicillin-streptomycin $(100 \mathrm{U} / \mathrm{ml})$ and $10 \%$ fetal bovine serum (Invitrogen, Carlsbad, CA, USA). In all experiments, cells were plated at $10^{5}$ cells $/ \mathrm{ml}$. One day after seeding, the medium was changed and the cells, at a $40-50 \%$ confluency, were treated with different concentrations of the plant extracts.

Cell proliferation and viability assays. Cells were plated in 96-well plates. At $24 \mathrm{~h}$ of treatment with the extracts, proliferation and toxicity were determined using the Cell Titer 96 non-radioactive cell proliferation kit and the CytoTox 96 non-radioactive cytotoxicity kit, respectively (Promega Corporation, Madison, WI, USA). The proliferation assay is an MTT-based method, which measures the ability of metabolically-active cells to convert tetrazolium salt into a blue formazan product and its absorbance is recorded at $570 \mathrm{~nm}$. The CytoTox 96 assay quantitatively measures the lactate dehydrogenase (LDH), a stable cytosolic enzyme that is released upon cell lysis. Released LDH in culture supernatants is measured with a coupled enzymatic assay which results in the conversion of a tetrazolium salt into a red formazan product, the absorbance of which is recorded at $490 \mathrm{~nm}$.

Flow cytometry analysis. The distribution of cells in the different phases of the cell cycle was evaluated by flow cytometry. Cells were plated in 60-mm tissue culture dishes. One day after treatment with the extracts, the cells were trypsinized, washed once with PBS and fixed with $70 \%$ ethanol for at least $2 \mathrm{~h}$ at $-20^{\circ} \mathrm{C}$. Fixed cells were washed with PBS, incubated with $200 \mu \mathrm{g} / \mathrm{ml}$ RNase A for $1: 15 \mathrm{~h}$ at $37^{\circ} \mathrm{C}$ and stained with propidium iodide (PI) obtained from Molecular Probes (Eugene, OR, USA). The stained cells were analyzed by a FACScan flow cytometer and the percentage of cells in pre $G_{1}, G_{0} / G_{1}, S$ and $G_{2} / M$ phases was determined using the CellQuest histogram analysis program. Cells that were less intensely stained than $\mathrm{G}_{1}$ cells in flow cytometric histograms were considered as apoptotic cells and marked as preG $_{1}$.

TUNEL assay. Terminal deoxy-transferase (tdT)-mediated dUTP nick end-labeling obtained from the Roche Diagnostic Corporation (Mannheim, Germany) was used to assess the induction of apoptosis by measuring the extent of fragmented DNA. One day after treatment, cells were collected, washed twice with PBS, fixed with $4 \%$ formaldehyde and diluted in
$1 \mathrm{X}$ PBS $(\mathrm{Vol} / \mathrm{Vol})$ at room temperature for $30 \mathrm{~min}$. The pellet was then washed with PBS and re-suspended in $100 \mu 1$ of solution containing $1 \mathrm{X}$ PBS, $0.1 \%$ sodium citrate and $0.1 \%$ Triton $\mathrm{X}-100$ for $2 \mathrm{~min}$. Fixed cells were then incubated with a TUNEL reaction mixture. The stained cells were analyzed by a FACScan flow cytometer.

Western blot analysis. Cellular protein extracts were prepared from cells, washed twice with PBS and scraped into an SDSlysis buffer (0.25 M Tris-HCl, pH 6.8, 20\% glycerol, 4\% SDS, $0.002 \%$ bromophenol blue, $10 \%$ B-mercaptoethanol). Protein concentrations were determined using a DC protein assay kit (Bio-Rad Laboratories, Hercules, CA, USA) according to the manufacturer's protocol. Equal amounts of total cellular proteins $(40 \mu \mathrm{g})$ were resolved by $12 \%$ SDSpolyacrylamide gel electrophoresis (PAGE), transferred onto polyvinylidene difluoride (PVDF) membranes (Amersham, Arlington, IL, USA) and then probed with primary antibodies including: anti-GAPDH, anti-actin (I-19), anti-Bcl2 (N-19), anti-p53 (FL-393), anti-p21 [(c-19)-G], anti-cyclinB ${ }_{1}$ (H-344) and anti-Bax followed by secondary antibodies conjugated with horseradish peroxidase (all purchased from Santa Cruz, CA, USA). Actin was used to ensure equal loading. The immunocomplexes were visualized using enhanced chemiluminescent kits obtained from Santa Cruz. To quantify protein bands, densitometry was done using ImageQuant software.

\section{In vivo DMH tumor experiment}

Animals and treatment. Female Balb/c mice, 6-9 weeks old, average weight $25 \mathrm{~g}$, were randomly distributed to the treatment and control groups. The mice were bred in the animal room of the Biology Department at the American University of Beirut. Mice were housed under optimum conditions of temperature set at $22 \pm 2^{\circ} \mathrm{C}$, with a 12 -h light/ dark cycle. They were kept in plastic cages covered with sawdust and had unrestricted access to a commercial mouse diet (24\% protein, $4.5 \%$ fat and $4 \%$ fiber) and tap water. All animal studies were conducted using a protocol approved by the Institutional Animal Care and Use Committee of the American University of Beirut. A total of 80 animals were divided into four groups: Group 1 mice were injected intraperitoneally (i.p.) with $0.9 \%$ sodium chloride $(n=10)$, Group 2 mice were injected i.p. with the crude water extract of $C$. ainetensis $(\mathrm{n}=10)$, Group 3 mice were injected subcutaneously (s.c.) with $20 \mathrm{mg} / \mathrm{kg}$ mouse body weight of the carcinogen DMH $(n=30)$ and Group 4 mice were injected i.p. with the crude extract 15 min prior to the injection of DMH $(n=30)$. $\mathrm{DMH}$ was dissolved in $0.9 \% \mathrm{NaCl}$ and was freshly prepared prior to injection. The duration of the experiment was for 30 weeks and injections were done once a week. The volume of the injected solution (saline or extract) was $0.3 \mathrm{ml}$. The longterm animal tumor experiment was performed with the undiluted crude extract which was not toxic to animals when injected i.p. for 10 consecutive days (data not shown).

Aberrant crypt foci and tumor counts. At week 10, mice were sacrificed by ether inhalation and colon tissue was processed so as to determine aberrant crypt foci $(\mathrm{ACF})$ counts $(n=8)$ by staining with Schiff's reagent. Briefly, the colons were excised, flushed with PBS and kept in ethanol : acetic acid 
A

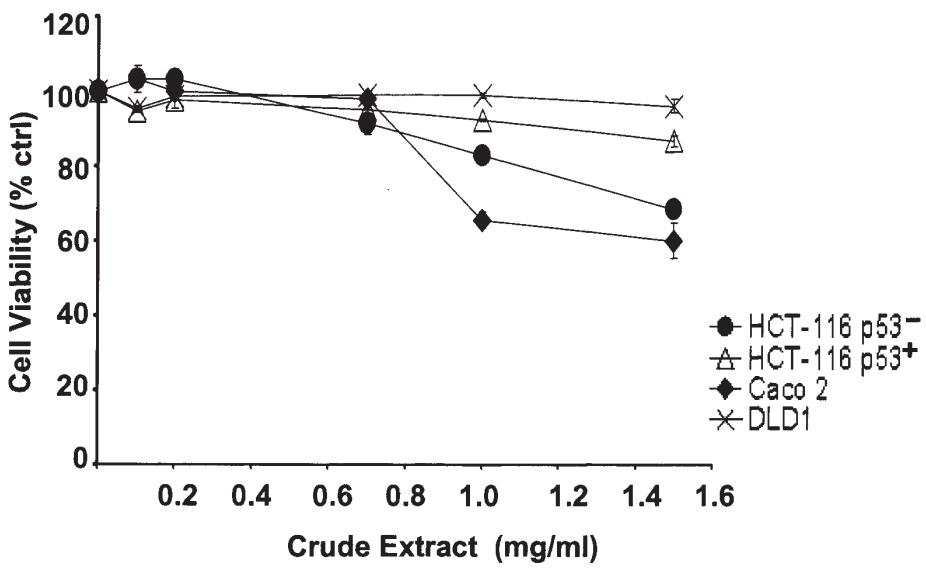

B

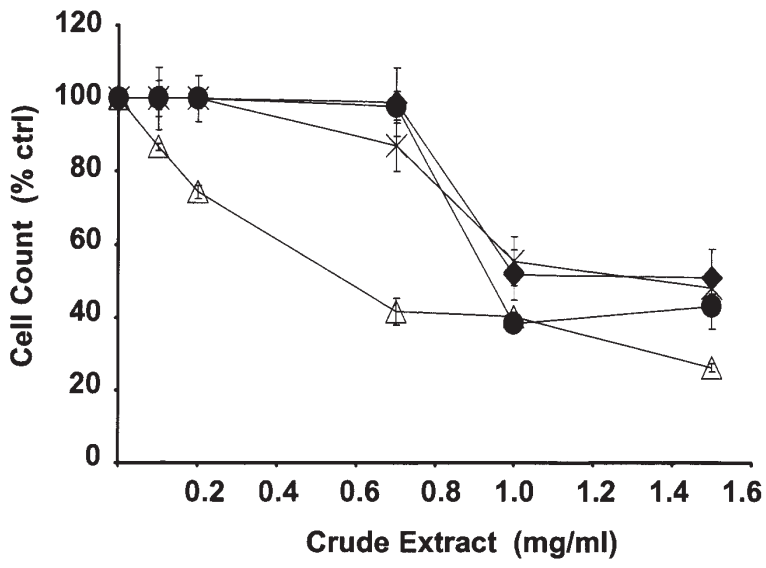

C

\begin{tabular}{|l|c|c|c|}
\cline { 2 - 4 } \multicolumn{1}{c|}{} & \multicolumn{3}{c|}{ Crude Extract Concentration } \\
\hline $\begin{array}{l}\text { Human Normal Intestinal } \\
\text { cells (FHs74lnt) }\end{array}$ & $\mathbf{0 . 2} \mathbf{~ m g / m l}$ & $\mathbf{0 . 7} \mathbf{~ m g} / \mathbf{m l}$ & $\mathbf{1 ~} \mathbf{~ g} / \mathrm{ml}$ \\
\hline Cell Viability (\% ctrl) & $\begin{array}{c}96.1 \pm \\
0.5\end{array}$ & $97.1 \pm 0.1$ & $100.5 \pm 0.5$ \\
\hline Cell Count (\% ctrl) & $100.7 \pm 3.2$ & $100.8 \pm 6.2$ & $75.6 \pm 0.7$ \\
\hline
\end{tabular}

Figure 1. Effect of $C$. ainetensis crude extract on HCT-116 (p53 $\left.3^{+/+}\right)$, HCT-116 (p53 $\left.3^{-/}\right)$, DLD1 and Caco-2 cell viability (A) and proliferation (B). Effect of $C$. ainetensis crude extract on human normal intestinal FHs74Int cell viability and proliferation (C). One day after seeding, cells were treated with increasing concentrations of extract. Cell growth and viability were determined 24 and 6 h, respectively using the Cell Titer 96 non-radioactive cell proliferation and cytotoxicity kits as described in Materials and methods. Each value represents the mean \pm SD of two separate experiments done in triplicate.

(3:1) at $4^{\circ} \mathrm{C}$ until analysis. At the time of analysis, colons were placed in $50 \%$ aqueous ethanol for $15 \mathrm{~min}$ at room temperature, transferred to distilled water for $10 \mathrm{~min}$, then to $1 \mathrm{~N} \mathrm{HCL}$ at $60^{\circ} \mathrm{C}$. After $7 \mathrm{~min}$ of incubation, colons were transferred to the Schiff's reagent for $10 \mathrm{~min}$. They were then rinsed in distilled water, cut longitudinally, pinned flat on a corkboard and stored overnight in $45 \%$ aqueous acetic acid at $4^{\circ} \mathrm{C}$. The following day, all colons were cut into equal parts (proximal, middle and distal), placed on microscopic slides and examined using fluorescent microscopy. ACF were identified, as being larger in diameter and having thickened crypt walls compared to neighboring normal crypts and their size and location was recorded. At weeks 20 and 30, colon tissue was processed to determine the tumor numbers $(n=8)$. Briefly, the colons were excised, flushed with PBS, rinsed with distilled water, cut longitudinally and visible tumors were counted using an optical microscope.

Statistical analysis. Results are expressed as means \pm standard error (SE). Statistical analysis was performed using the SPSS student version 11.0 software package. Comparisons between Groups 4 and 3 were evaluated using ANOVA followed by the Dunnett test. The level of significance was set at $0.05,0.01$ or 0.0001 as indicated.

\section{Results}

Centaurea ainetensis crude extract selectively inhibits cancer cell proliferation. Four human colon cancer cell types (HCT-
116 p53 $3^{++}$, HCT-116 p53 $3^{-/}$, DLD-1 and Caco-2) were treated with increasing concentrations $(0.1-1.5 \mathrm{mg} / \mathrm{ml})$ of the methanolic crude extract of $C$. ainetensis and the effects on cytotoxicity and cell proliferation were monitored. The $C$. ainetensis crude extract and vehicle treatment were found to be relatively non-toxic to all cell lines at all tested concentrations (Fig. 1A). The extract inhibited the proliferation of all four colon cancer cell lines in a dose-dependent manner (Fig. 1B) with $\mathrm{IC}_{50}$ values ranging between 0.5 and $0.9 \mathrm{mg} / \mathrm{ml}$. Notably, the $C$. ainetensis extract did not induce significant growth inhibition or toxicity in normal human intestinal epithelial cells (Fig. 1).

Centaurea ainetensis crude extract induces cell cycle arrest and apoptosis. We further investigated the mode of action of the crude extract on cellular parameters, including cell cycle distribution and apoptosis, in the HCT-116 (p53 $\left.3^{+/+}\right)$human colon cancer cell lines. Among the host of colon cancer cell lines used, the HCT-116 cell line appeared to be the most sensitive to the crude extract inhibitory effect. Cell cycle profiles of cells treated at various concentrations of the extract were obtained by flow cytometry of DNA content by PI staining at $24 \mathrm{~h}$. This analysis shows that the $C$. ainetensis crude extract induced a progressive increase in the proportion of sub- $\mathrm{G}_{1}$ cells with a maximum induction of $41 \%$ at $1 \mathrm{mg} / \mathrm{ml}$ (Fig. 2A).

The nature of cell death observed was confirmed by utilizing the TUNEL assay, which confirmed apoptosis 
A
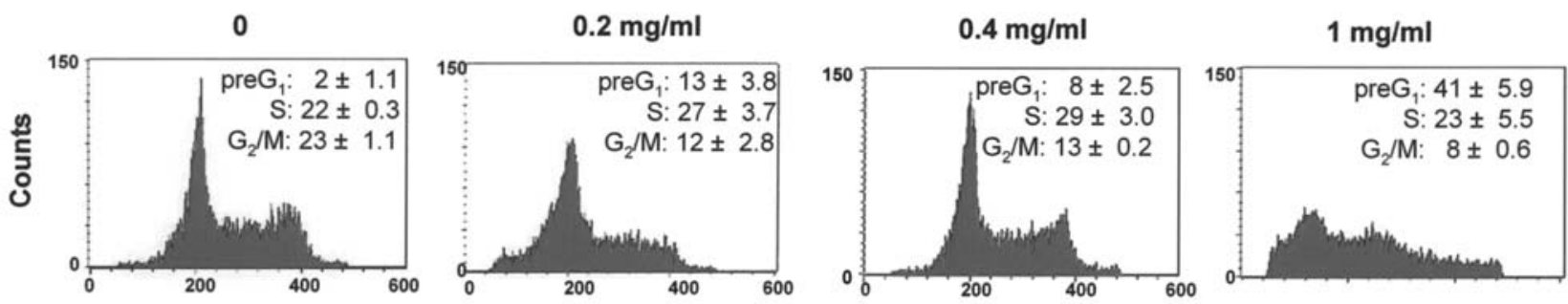

B
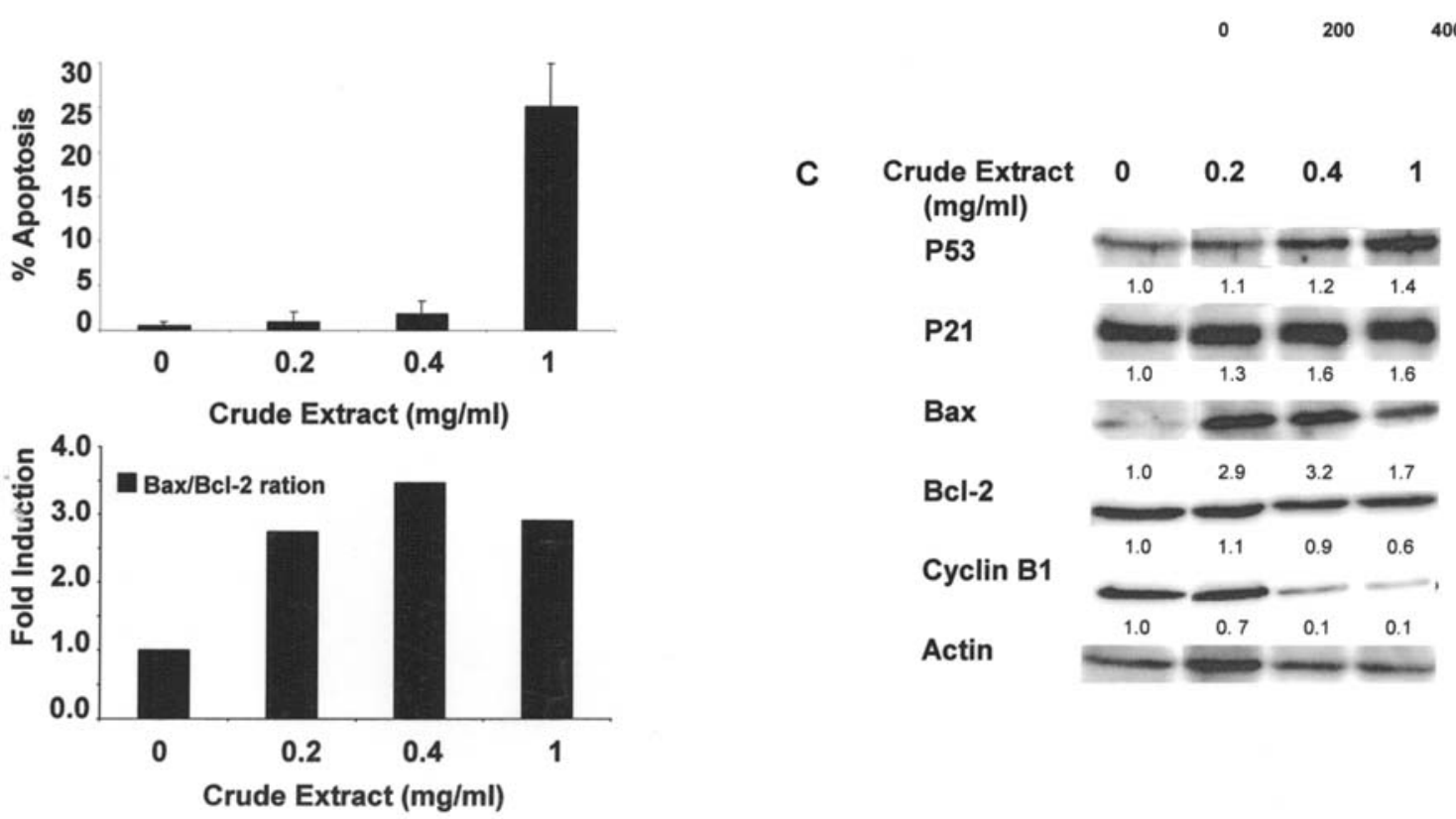

Figure 2. Effect of $C$. ainetensis crude extract on cell cycle progression (A) and apoptosis induction in HCT-116 cells. One day after seeding, cells were treated with increasing concentrations of the extract for $24 \mathrm{~h}$. Distribution of the cells in $\mathrm{preG}_{1}, \mathrm{~S}$, and $\mathrm{G}_{2} / \mathrm{M}$ phases was analyzed by flow cytometry and the induction of apoptosis was determined using the TUNEL assay as described in Materials and methods. Effects of the C. ainetensis crude extract on the protein expression of p53, p21, Bax, Bcl-2, and cyclin $\mathrm{B}_{1}$ in HCT-116 cells. One day after seeding, cells were treated with increasing concentrations of the extract for $24 \mathrm{~h}$. Cell lysis and Western blotting were performed as described in Materials and methods. Each value represents the mean \pm SD of two separate experiments done in duplicate. Bands were quantified and expressed as a ratio of control cells set to one.

induction (Fig. 2B). HCT-116 treated cells underwent a significant amount of apoptosis and the percentage of TUNEL positive cells was $26 \%$ at $1 \mathrm{mg} / \mathrm{ml}$ treatment (Fig. 2B).

Centaurea ainetensis crude extract modulates key cell cycle and apoptotic regulators. Several studies have shown an association between cell cycle deregulation and carcinogenesis. Inhibition of the cell cycle was appreciated as a target for cancer treatment $(11,15)$. Consequently, the effect of the $C$. ainetensis extracts on cellular growth inhibition and alterations in the protein expression of key cell cycle and apoptotic mediators (cyclin $\mathrm{B}_{1}, \mathrm{p} 21$, p53, Bax and Bcl-2) was investigated.

Upon treating the HCT-116 cells with the $C$. ainetensis crude extract, we observed a dose-dependent decrease in the cyclin $\mathrm{B}_{1}$ expression ranging from $80-90 \%$ at 0.4 and $1 \mathrm{mg} / \mathrm{ml}$, respectively (Fig. 2). Conversely, p21 and p53 proteins levels were induced upon treatment with 0.4 and $1 \mathrm{mg} / \mathrm{ml}$ of the plant extract (Fig. 2). Then, we monitored changes in proapoptotic Bax and anti-apoptotic Bcl-2 proteins upon treatment with the plant extract. While Bax is up-regulated by $\mathrm{p} 53, \mathrm{Bcl}-2$ proteins prevent the release of apoptotic factors. Hence, an increase in pro-apoptotic over anti-apoptotic proteins favors apoptosis and leads to the release of cytochrome $\mathrm{c}$ and promotes cell death. HCT-116 cells treated with the extract for $24 \mathrm{~h}$ resulted in an increase in the Bax/ $\mathrm{Bcl}-2$ ratio ranging from 2 to 3 folds (Fig. 2).

Centaurea ainetensis effect in vivo on DMH-induced colonic tumors in mice

Centaurea ainetensis extracts or DMH have no effect on body weight gain in mice. Intraperitoneal injections of Balb/c mice with the non-diluted crude extracts of $C$. ainetensis for 10 consecutive days did not affect their body weight or induce death (data not shown). Therefore, we performed the long-term animal tumor experiment with the undiluted crude extracts. In addition, DMH-injected groups gained normal body weight during the entire experimental period (data not shown).

Centaurea ainetensis inhibited tumor formation in DMHinduced colon cancer. At week 10, after fixation for at least $24 \mathrm{~h}$ at $4^{\circ} \mathrm{C}$, the colons from all animals were equally divided into proximal, middle and distal segments and stained with Schiff's reagent. The total number of ACF was recorded in all treatment groups. As expected, no ACF were observed in animals given the plant extract alone or in those treated with 
A
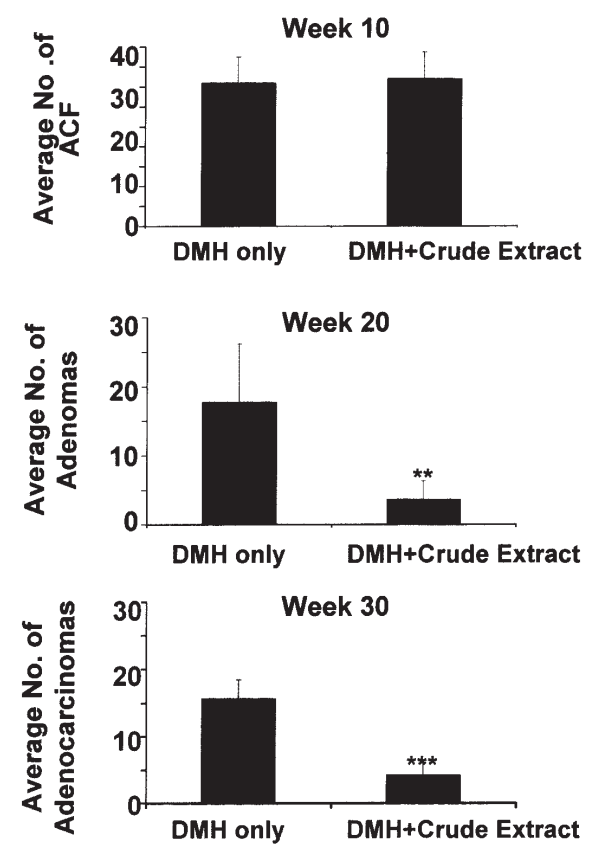

$0.9 \% \mathrm{NaCl}$ (data not shown). After 10 weeks of DMH treatment, all animals developed ACF. The size of ACF located in the middle and distal colon was recorded in $\mathrm{mm}^{2}$ for all different groups. Although groups treated with the crude extract 15 min prior to the DMH injection did not show a significant decrease at 10 weeks in the total number of ACF (Fig. 3A), the average size of ACF present in the colon was significantly reduced $(\mathrm{p}<0.0001)$ as compared to the DMH-treated group (Fig. 3B).

At 20 and 30 weeks of treatment and using an optical microscope, tumors were observed in all DMH-treated mice. No such lesions were noted in animals treated with either plant extract or saline alone (data not shown). The administration of the extract $15 \mathrm{~min}$ prior to the $\mathrm{DMH}$ injection decreased the average number of adenomas by $79 \%$ at week $20(p<0.001)$ and the average number of adenocarcinomas by $73 \%$ at week $30(\mathrm{p}<0.0001)$ as compared to the carcinogen-treated controls (Fig. 3A).

The bio-guided fractionation of Centaurea ainetensis and isolation of Salograviolide A. The Centaurea ainetensis extract induces antiproliferation and apoptosis in human colon cancer cells and reduces colon tumor formation in mice. We have used cell proliferation assays to guide our attempts to isolate a purified molecule from this extract. The methanolic extract used in the initial screening studies was fractionated (Fig. 4) and the antiproliferative effects of four fractions (I.1, I.2, I.3 and I.4) were investigated in HCT-116. Fraction I.2 significantly inhibited the growth of HCT-116 cells by almost $80-90 \%$ without being toxic to normal intestinal cells (data not shown). Therefore, further bioassay-guided fractionation was done using fraction I.2. A total of six fractions resulted from the subfractionation of I.2, all of which were tested in HCT-116 cells. Results showed that the I.2.2 subfraction, exerted significant growth inhibitory effects in the HCT-116 cells (data not shown). The
B

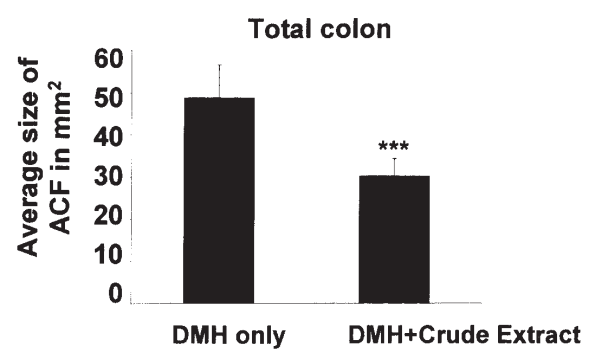

Figure 3. The effect of the crude Centaurea ainetensis extract on ACF numbers/colon at week 10 and on adenomas and adenocarcinomas numbers at weeks 20 and 30 , respectively ( $n=8$ mice) (A). The effect of the crude Centaurea ainetensis extract on the mean sizes of ACF/colon after 10 weeks of treatment ( $\mathrm{n}=8$ mice) (B). Colons were stained with Schiff's reagent and ACF were counted using fluorescence microscopy. Adenomas and adenocarcinomas were examined using an optical microscope. ACF sizes were recorded in $\mathrm{mm}^{2}$ using fluorescent microscopy. The mean difference is significant at the 0.05 level; $* * \mathrm{p}<0.001, * * * \mathrm{p}<0.0001$.

purification and identification of the I.2.2 subfraction using a solid phase extraction and spectroscopic analysis led to the isolation of Salograviolide A (Fig. 4). Salograviolide A was not cytotoxic to the four cell lines tested at concentrations up to $16 \mu \mathrm{g} / \mathrm{ml}$ (Fig. 5A). Growth inhibition by Salograviolide A was dose-dependent and reached $\sim 75 \%$ inhibition at $16 \mu \mathrm{g} / \mathrm{ml}$ (Fig. 5B). Non-cytotoxic concentrations of Salograviolide A of up to $16 \mu \mathrm{g} / \mathrm{ml}$ only caused a $30 \%$ growth suppression in normal human intestinal cells (Fig. 5C). An analysis of cell cycle distribution of PI-stained DNA content showed that Salograviolide A increased preG $_{1}$ cells in the HCT-116 cell lines (Fig. 6A). This was further supported using the TUNEL assay whereby we showed that the induced increases in the pre- $\mathrm{G}_{1}$ phases are due to apoptosis (Fig. 6A).

\section{Discussion}

We showed that the crude extract of $C$. ainetensis inhibits tumor formation in the 1,2-dimethylhydrazine mouse model of colon cancer. Furthermore, the crude extract and the isolated guaianolide, Salograviolide A, obtained by bioassay-guided fractionation induce specific antiproliferation effects against several human colon cancer cells. We demonstrated that Salograviolide A derived from this plant has no cytotoxic properties on normal cells, indicating its selectivity to cancer cells.

Cellular and molecular evidence obtained from this study indicate that extracts of the indigenous $C$. ainetensis induce apoptosis in human colon cancer cells. Extract-induced programmed cell death is associated with an increase in p53 and p21 protein expression. The pro-apoptotic protein Bax and the anti-apoptotic protein Bcl-2 are known to act at the mitochondrial level to control membrane permeability, which is a fundamental event in apoptosis signaling. The upregulation of Bax and down-regulation of Bcl-2 favor the proapoptotic over the anti-apoptotic response in the cell leading 


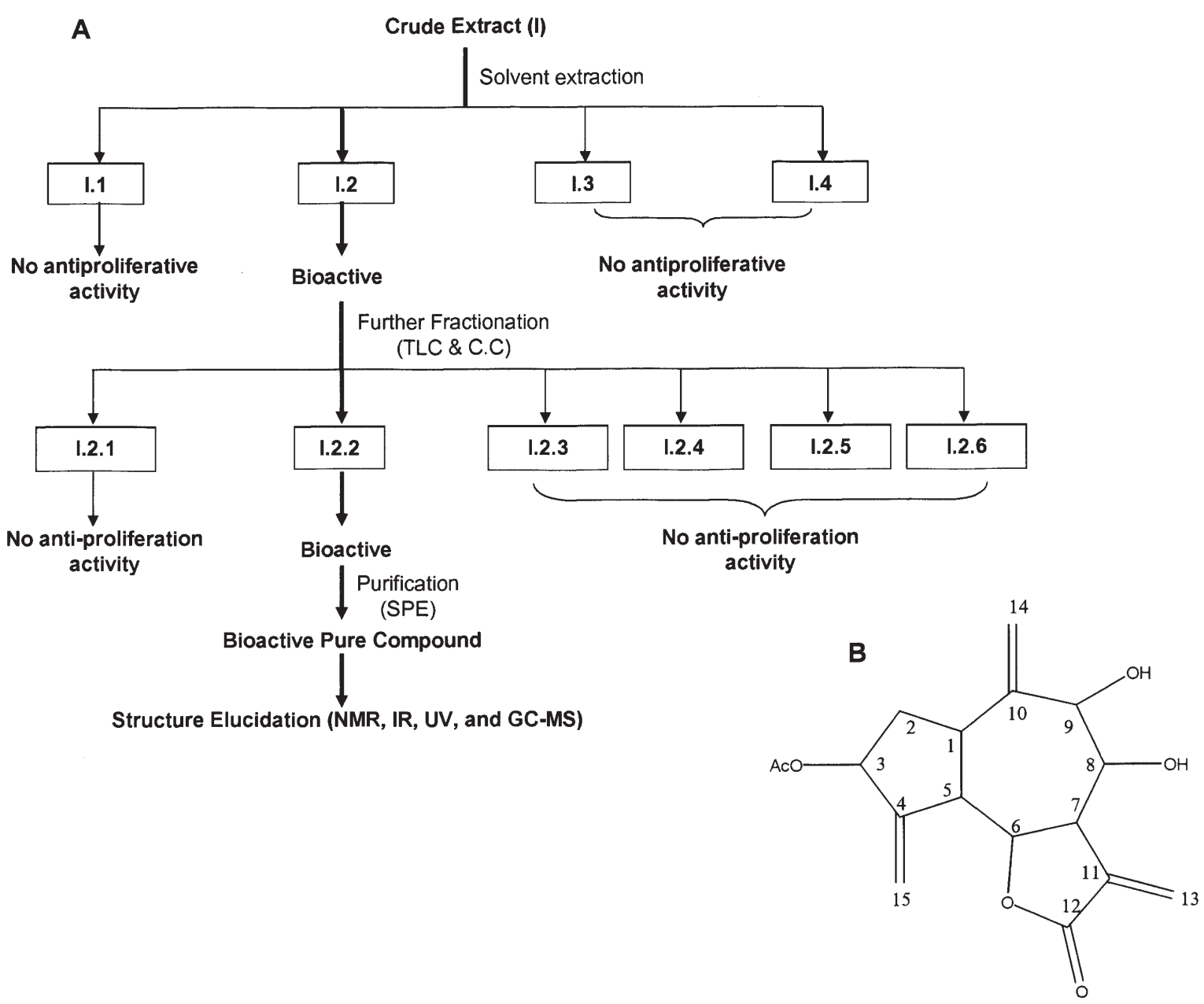

Figure 4. (A) Scheme presenting the bioguided fractionation of the methanol extraction of Centaurea dried material and the identification of the anti-cancer guaianolide, Salograviolide A. 'Bioactive' indicates the anti-proliferation effect and 'No activity' indicates a marginal or anti-proliferation effect by cancer cells. (B) Chemical structure of Salograviolide A.

to the release of cytochrome $\mathrm{c}$ and promoting cell death. Notably, a remarkable increase in the Bax/Bcl-2 ratio occurred in the crude extract-treated tumor cells, which correlated with the induction of apoptosis observed in the HCT-116 colon cancer cell lines. Furthermore, the expression of the cyclin $\mathrm{B}_{1}$ protein, the down-regulation of which is fundamental for mitotic exit and cytokinesis (16), is significantly reduced in extract-treated HCT-116 cells. Unlike most known chemotherapeutic drugs associated with strong toxicity, $C$. ainetensis showed a high selectivity against cancer cells with no apparent toxic effects on normal cells at the tested concentrations. This differential effect makes the plant extract a potentially harmless agent that can effectively inhibit colon cancer development.

The stepwise development of colorectal carcinogenesis from dysplastic ACF to adenomas and adenocarcinomas offers multiple opportunities for assessment and intervention, particularly in animal models. Experimental colonic tumors induced by $\mathrm{DMH}$ are of epithelial origin with a similar histology, morphology and anatomy to human colonic neoplasms and, therefore, are regarded as an excellent model for anticancer studies (17). DMH-induced colon cancer has been used extensively to study the antitumor effect of plantderived drugs $(18,19)$. The possible tumor inhibitory effect of
C. ainetensis in DMH-induced colorectal carcinogenesis was investigated by treating mice weekly with the extract prior to the DMH injection. After the DMH injections over a 10-week period, $100 \%$ of the mice treated with both $\mathrm{DMH}$ and $\mathrm{DMH}^{+}$ of the plant extract developed ACF in the colon. ACF are potential markers of early tumor growth and are considered to be useful intermediate biomarkers for the modifying effect of certain natural or synthetic compounds on chemicallyinduced carcinogenesis (20). The decrease in the average number of ACF in the colon from the extract was not statistically significant. Despite the absence of the extract inhibitory effect on the ACF number, it notably reduced the mean size of ACF.

Notably, the extract substantial inhibition of tumor formation was observed as early as 20 weeks. The inhibitory effects on cancer formation but not on benign ACF development suggest that the extract may be active at later stages of tumor development rather than early ones. This activity resembles that of rofecoxib, a highly selective inhibitor of cyclooxygenase-2 that was shown to inhibit the later stages of DMH-induced colon carcinogenesis in Wistar rats (21).

Several studies suggest that the genus Centaurea is a house of many secondary metabolites exhibiting several therapeutic values (11). The biological activity of $C$. nicoli, 

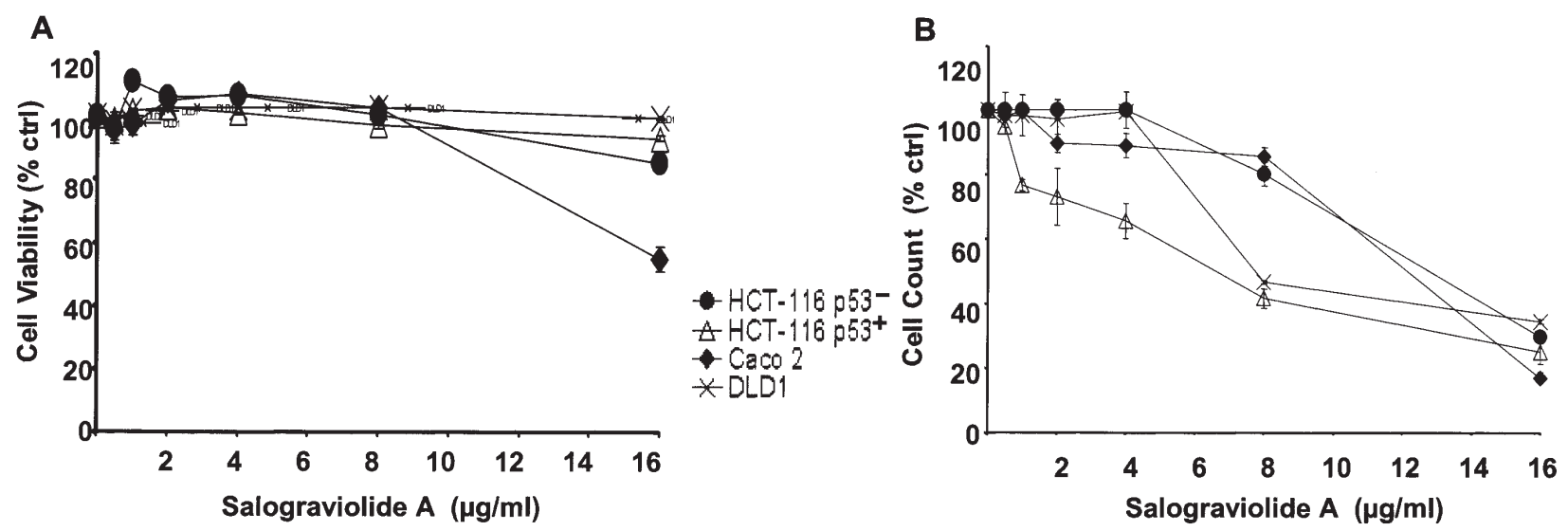

\begin{tabular}{|l|c|c|c|}
\cline { 2 - 4 } \multicolumn{1}{c|}{} & \multicolumn{3}{c|}{ Salograviolide A Concentration } \\
\hline $\begin{array}{l}\text { Human Normal Intestinal } \\
\text { cells (FHs74lnt) }\end{array}$ & $\mathbf{4} \boldsymbol{\mu g} / \mathrm{ml}$ & $\mathbf{8} \boldsymbol{\mu g} / \mathrm{ml}$ & $\mathbf{1 6} \boldsymbol{\mu g} / \mathrm{ml}$ \\
\hline Cell Viability (\% ctrl) & $103 \pm 0.18$ & $102 \pm 0.10$ & $98.4 \pm 0.13$ \\
\hline Cell Count (\% ctrl) & $107 \pm 4.47$ & $105 \pm 7.06$ & $68.5 \pm 5.06$ \\
\hline
\end{tabular}

Figure 5. Effects of increasing concentrations of the molecule Salograviolide A on HCT-116 (p53 $\left.{ }^{+/+}\right)$, HCT-116 (p53 $3^{-/-}$, DLD1 and Caco-2 cell viability (A) and growth (B). Cytotoxicity and growth inhibitory effect of Salograviolide A on normal human intestinal cells (C). One day after seeding, cells were treated with increasing concentrations of indicated fractions and Salograviolide A for 6 (viability) and $24 \mathrm{~h}$ (cell growth). Cell growth and viability were determined using the Cell Titer 96 non-radioactive cell proliferation kit and the CytoTox 96 non-radioactive cytotoxicity kit, respectively, as described in Materials and methods. Each value represents the mean \pm SD of two separate experiments done in triplicate.

\section{A Cell cycle $24 \mathrm{~h}$ post treatment}

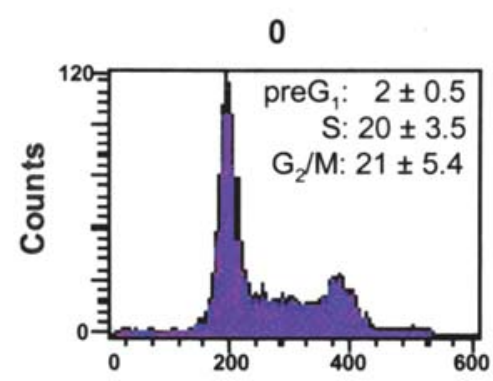

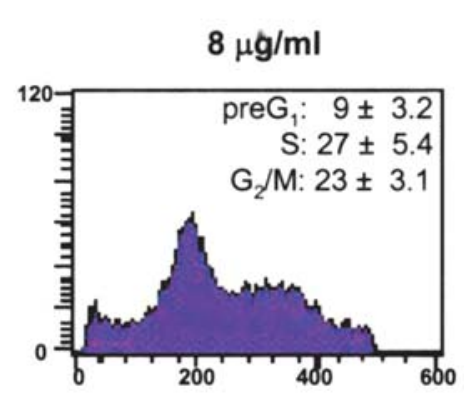

Figure 6. Effect of the molecule Salograviolide A on HCT-116 cells, cell cycle distribution (A) and apoptosis-induction (B). One day after seeding, cells were treated with $8 \mu \mathrm{g} / \mathrm{ml}$ Salograviolide A for $24 \mathrm{~h}$. Distribution of cells in $\mathrm{preG}_{1}, \mathrm{~S}$, and $\mathrm{G}_{2} / \mathrm{M}$ phases was analyzed by flow cytometry and the induction of apoptosis was determined using the TUNEL assay, as described in Materials and methods. Each value represents the mean \pm SD of two separate experiments done in duplicate.

specifically its antifungal effects, has been attributed to the Salograviolide A molecule present in this plant (22). In this study, purified Salograviolide A, which belongs to the guaianolide Sesquiterpene Lactones from $C$. ainetensis was responsible, at least in part, for the crude extract biological activity. Sesquiterpene Lactones are the most widely investigated metabolites in Centaurea plants. They exhibit considerable growth inhibitory activities against MCF-7 breast cancer and H460 lung cancer cell lines when isolated from C. zuccariniana, C. Achaia, C. thessala and C. deusta (11). Furthermore, lactones derived from the aerial parts of
C. thessala and $C$. attica possess a pronounced antifungal activity against nine fungal species (23). Studies have attributed the observed antifungal activity of the plant-derived lactones to the relatively low polarity of Sesquiterpene Lactone molecules (24).

The antitumor activities of Salograviolide A are new activities identified for this molecule. Although 5 distinct guaianolides isolated from $C$. nicoli, a plant endemic to Yugoslavia and Albania, were identified, only Salograviolide A was shown to possess antifungal activities against seven fungi (21). 
In conclusion, our results are the first to describe a potent antiproliferative effect of the $C$. ainetensis extract against colon cancer. In vitro, the crude extract inhibited the growth of several human colon cancer cells. In vivo, this extract reduced the mean size of $\mathrm{ACF}$ and decreased tumor formation in the DMH model of colon cancer. In addition, this is the first successful attempt to isolate the molecule Salograviolide A from the extract of $C$. ainetensis that, as we showed, is responsible for its biological activity. Salograviolide A induces apoptosis in human colon cancer cells and thus merits further investigation as both a chemoprotective agent as well as a potential anticancer agent. Future studies will focus on investigating the molecular targets and effectors, which are modulated by Salograviolide A to induce apoptosis.

\section{Acknowledgements}

This work was supported by grants from UNISANTIS and the research was conducted under the direction of the Initiative for Biodiversity Studies in Arid Regions (IBSAR) at the American University of Beirut, Lebanon. We thank the members of the Central Research Science Laboratory for their help in using the flow cytometer, NMR and HPLC.

\section{References}

1. Lee H-J, Lee E-O, Rhee YH, Ahn KS, Li GX, Jiang C, Lü J and Kim SH: An oriental herbal cocktail, ka-mi-kae-kyuk-tang, exerts anti-cancer activities by targeting angiogenesis, apoptosis and metastasis. Carcinogenesis 27: 2455-2463, 2006.

2. Gali-Muhtasib HU, Diab-Assaf M, Bolitze C, Al-Hmaira J, Hartig R, Roessner A and Schneider-Stock R: Thymoquinone extracted from black seed triggers apoptotic cell death in human colorectal cancer cells via a p53-dependent mechanism. Int J Oncol 25: 857-866, 2004.

3. Rouwayha A: Alatadawi Bil Aa'shab. Dar El Qualam, Beirut, Lebanon, 1981.

4. Rouwayha A: Herbal Treatment. Dar El Qualam, Beirut, Lebanon, pp1-253, 1983.

5. Kaij-a-Kamb M, Amoros M and Girre L: The chemistry and biological activity of the genus Centaurea. Pharm Acta Helv 67: 178-188, 1992.

6. Mabberlay DJ: The Plant-Book. 2nd edition Cambridge University Press, Cambridge, p440, 1997.

7. Karamenderes C, Konyalioglu S, Khan S and Khan IA: Total phenolic contents, free radical scavenging activities and inhibitory effects on the activation of NF-kappa B of eight Centaurea L. species. Phytother Res 21: 488-491, 2007.

8. Buruk K, Sokmen A, Aydin F and Erturk M: Antimicrobial activity of some endemic plants growing in the Eastern Black Sea Region, Turkey. Fitoterapia 77: 388-391, 2006.
9. Skliar MI, Toribio MS and Oriani DS: Antimicrobial activity of Centaurea diffusa. Fitoterapia 76: 737-739, 2005.

10. Viguera Lobo JMY and Casabuena PA: Hypoglycemic action in the genus Centaurea II Attempt at the separation of the active principle. Farmacognosia 13: 223-234, 1953.

11. Koukoulitsa E, Skaltsa H, Karioti A, Demetzos C and Dimas K: Bioactive sesquiterpene lactones from Centaurea species and their cytotoxic/cytostatic activity against human cell lines in vitro. Planta Med 68: 649-652, 2002.

12. Lee KH, Ibuka T, Wu RY and Geissman TA: Structureantimicrobial activity relationship among the sesquiterpene lactones and related compounds. Phytochemistry 16: 1177-1181, 1977.

13. Giordano OS, Pestchanker MJ, Guerreiro E, Saad JR, Enriz RD, Rodriguez AM, Jauregui EA, Guzman J, Maria AO and Wendel GH: Structure-activity relationship in the gastric cytoprotective effect of several sesquiterpene lactones. J Med Chem 35: 2452-2458, 1992.

14. Akbar S, Fries DS and Malone MH: Effect of various pretreatments on the hypothermic activity of repin in naive rats. $J$ Ethnopharmacol 49: 91-99, 1995.

15. Senderowicz AM and Sausville EA: Preclinical and clinical development of cyclin-dependent kinase modulators. J Natl Cancer Inst 92: 376-387, 2000.

16. Takizawa CG and Morgan DO: Control of mitosis by changes in the subcellular location of cyclin B1-CDK1 and Cdc25C. Curr Opin Cell Biol 12: 658-665, 2000.

17. Maskens AP: Histogenesis and growth pattern of 1,2dimethylhydrazine-induced rat colon adenocarcinoma. Cancer Res 36: 1585-1592, 1976.

18. Smith TK, Mitchen R and Johnson IT: Effects of Brassica vegetable juice on the induction of apoptosis and aberrant crypt foci in rat colonic mucosal crypts in vivo. Carcinogenesis 24: 491-495, 2003.

19. Weed HG, McGandy RB and Kennedy AR: Protection against dimethylhydrazine-induced adenomatous tumors of the mouse colon by the dietary addition of an extract of soybeans containing the Bowman-Birk protease inhibitor. Carcinogenesis 6: 1239-1241, 1985.

20. Archana S, Samit G and Sukta D: Modulatory influence of garlic and tomato on cyclooxygenase-2 activity, cell proliferation and apoptotis during azoxymethane-induced colon carcinogenesis in rat. Cancer Lett 208: 127-136, 2004.

21. Perse M, Zeibic A and Cerar A: Rofecoxib does not inhibit aberrant crypt foci formation but inhibits later steps in the development of experimental colorectal cancer: Rofecoxib in experimental colon cancer. Scand J Gastroenterol 40: 61-67, 2005.

22. Vajs V, Todorovic N, Ristic M, Tesevic V, Todorovic B, Janackovic P, Marin P and Milosavljevic S: Guaianolides from centaurea nicoli: antifungal activity. Phytochemistry 52: 383-386, 1999.

23. Skaltsa H, Lazari D, Panagouleas C, Georgiadou E, Garcia B and Sovokic M: Sesquiterpene lactones from Centaurea thessala and Centaurea attica Antifungal activity. Phytochemistry 55: 903-908, 2000.

24. Barrero AF, Oltra JE, Alvarez M, Raslan DS, Saude DA and Akssira M: New sources and antifungal activity of sesquiterpene lactones. Fitoterapia 71: 60-64, 2000. 